
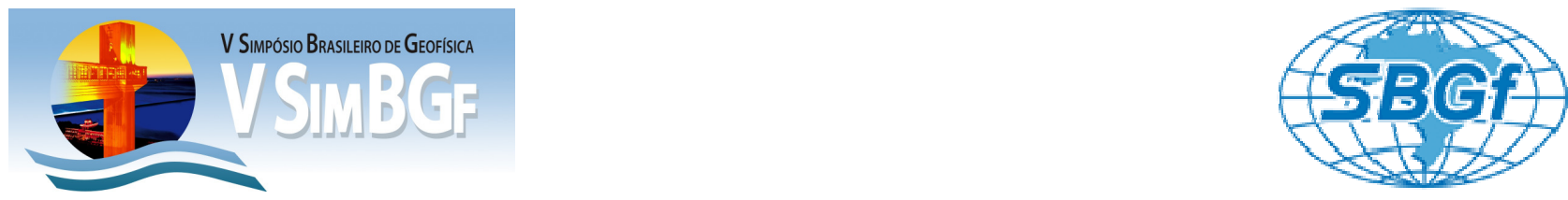

\title{
Condutividade Térmica em Rochas e Sedimentos do Complexo Juiz de Fora
}

Felipe P. Santos (felipereira.santos@gmail.com), Gleison M. Santos (gleisoncml@hotmail.com), Julhia M. P. Silva (julhia silva@hotmail.com), Priscila C. O. Campos (priscila.campoos@yahoo.com.br) e Antonio J. L. Gomes (antonio.gomes@ufvjm.edu.br) - Universidade Federal dos Vales do Jequitinhonha e Mucuri

Copyright 2012, SBGf - Sociedade Brasileira de Geofísica

Este texto foi preparado para a apresentação no V Simpósio Brasileiro de Geofísica, Salvador, 27 a 29 de novembro de 2012. Seu conteúdo foi revisado pelo Comitế Técnico do V SimBGf, mas não necessariamente representa a opinião da SBGf ou de seus associados. É proibida a reprodução total ou parcial deste material para propósitos comerciais sem prévia autorização da SBGf.

\section{Resumo}

Apresenta-se neste trabalho resultado de uma avaliação compilada de medidas de condutividade térmica do Complexo Juiz de Fora. Os dados analisados foram obtidos de trabalhos já publicados e levantados em revisões bibliográficas relevantes, todas relativas à área de estudo. Os valores obtidos foram determinados através dos métodos de Fonte Linear de Calor e Fonte Planar de Calor. Foram considerados neste estudo os principais tipos litológicos já estudados e publicados sobre o complexo. Os valores levantados das rochas e sedimentos apontaram para um intervalo compreendido entre 1,6 e 4,7 W/m.K e com a nova análise, chegou-se a um valor médio de $3,2 \mathrm{~W} / \mathrm{m}$.K para a condutividade térmica no Complexo Juiz de Fora. $\mathrm{Na}$ ausência de dados locais ou mais precisos, este valor médio poderá ser utilizado em estudos referentes a avaliações geotérmicas em locais que estão sob o Complexo Juiz de Fora.

\section{Introdução}

Conhecer a condutividade térmica do Complexo Juiz de fora atende a uma grande demanda de pesquisas. Este complexo é uma formação geológica de considerável extensão, que abrange com maior notoriedade parte dos Estados de Minas Gerais e Rio de Janeiro.

Para a avaliação de recursos geotermais faz-se necessário conhecer o valor da condutividade térmica do local ou da região. São utilizados dois métodos para a determinação da condutividade térmica: $O$ da Fonte Linear de Calor e o da Fonte Planar de Calor (Gomes, 2003).

As unidades geológicas que pertencem ao Complexo Juiz de Fora são consideradas em sua maioria pertencentes ao período geológico Arqueano. Este Complexo é composto por ortognaisses com paragêneses da fácies granulito, e tendo como litotipo característico gnaisse enderbítico, granulação média, verde escuro, com bandamento centimétrico e intercalações máficas (Silva et al, 2007).

A geologia do complexo é caracterizada pela presença de gnaisses, gnaisses granulíticos, granulitos básicos, biotita gnaisse, granitoides, charnockitos, anfibolitos, dentre outros tipos litológicos incluindo os intrusivos e porções sem diferenças determinadas do Complexo Paraíba do Sul.
Entretanto, o complexo de Juiz de Fora é uma faixa encurvada constituída de enderbitos, charnokitos, granitoides, quartzo-dioritos, dioritos, gabros e noritos em meio a gnaisses e migmatitos granulíticos. (Hasui et al 1984).

Rangel da Silva et al (1987) designam o complexo de Juiz de Fora como o conjunto de rochas pertencentes à fácies granulito e anfibolito médio a forte, constituído por granada-biotita gnaisses, gnaisses a hiperstênio, gnaisses quartzo-feldspálticos e biotita gnaisses. Apresentamos a seguir na Figura (1) parte da região do Complexo Juiz de Fora, em imagem recortada, do Mapa Geológico de Minas Gerais (COMIG, 1994)

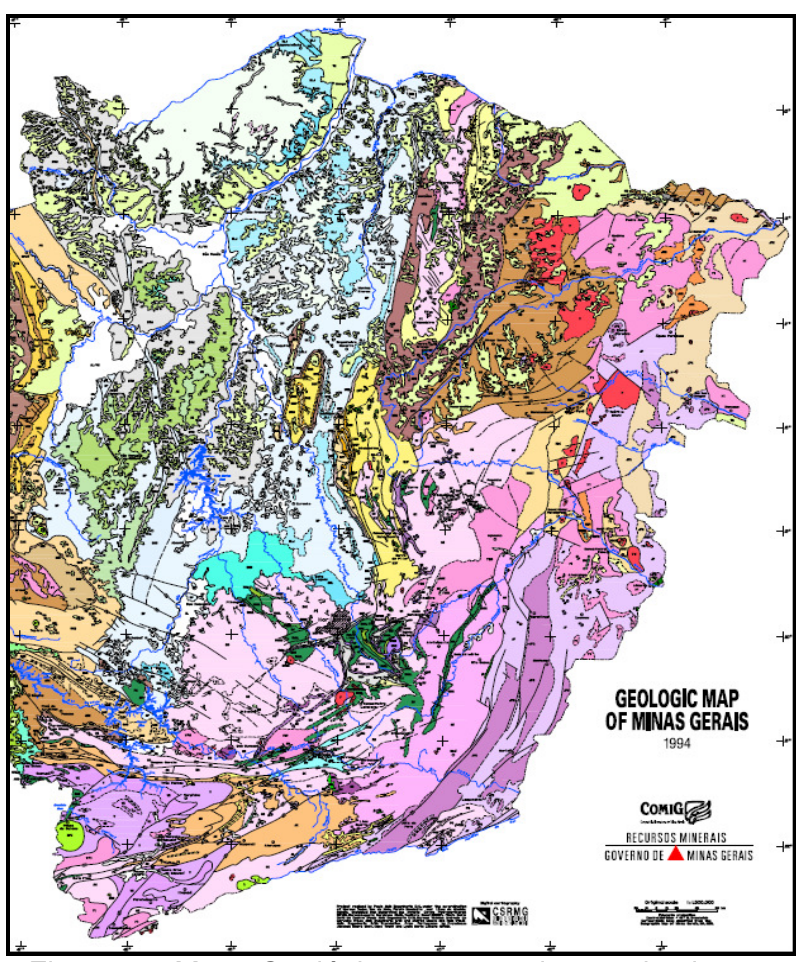

Figura 1 - Mapa Geológico com a região predominante do Complexo Juiz de Fora (adaptado de COMIG, 1994).

\section{Metodologia}

Para diversos estudos relacionados a processos térmicos da matéria e consequentemente referentes às formações geológicas, é preciso que se conheçam as variáveis que circundam o âmbito de estudo ou o sistema analisado. Nesse contexto conhecer a condutividade térmica de um material, ou de um meio geológico, é uma das mais importantes propriedades físicas dos materiais, e a medida da mesma permite a determinação do fluxo de 
calor e do cálculo de avaliações de recursos geotermais (Gomes, 2009).

A condutividade térmica de uma região pode não ser precisa levando em consideração apenas um fator, como analisamos anteriormente a litologia. Para resultados mais precisos, são feitas pesquisas de campo e recolhidas amostras, sendo utilizados dois métodos para a determinação da condutividade térmica: $O$ da Fonte Linear de Calor e o da Fonte Planar de Calor.

a) Fonte Linear de Calor: O princípio deste método tem como base a solução da equação de transmissão de calor apropriada para o caso de fonte linear de calor num meio infinito (CARSLAW e JAEGER, 1959) apresentada a seguir:

$$
T=\frac{Q \ln (t)}{4 \pi A}+c
$$

Onde:

Q é a taxa de produção de calor por unidade de tempo e comprimento;

$\lambda$ a condutividade térmica;

t o tempo após o início do ensaio;

$\mathrm{T}$ a temperatura.

A relação linear entre a temperatura $(T)$ e o logaritmo de tempo (t) permite a determinação da condutividade térmica da amostra, desde que se conheça o valor de taxa de taxa de aquecimento (Q). Um ensaio inicial com uso de um material padrão cuja condutividade térmica seja conhecida permite a determinação do valor efetivo de $Q$. A equação (1) pode ser facilmente adaptada para caso do meio semi-infinito (isso é: o fluxo de calor ocorre em geometria de $2 \pi$ ):

$$
T=\frac{Q \ln (t)}{2 \pi \lambda}+c
$$

Ambos os casos representados nas equações (1) e (2) podem ser utilizados para determinação de condutividade térmica. Contudo, questões práticas na preparação de amostras determinam a escolha. Geralmente, o caso representado pela equação (1) é utilizado para amostras de sedimentos e de calha enquanto o caso da equação (2) é mais adequado para amostras sólidas.

No trabalho realizado por (GOMES E HAMZA, 2003), ao utilizar o método de Fonte de calor para a determinação da condutividade térmica no estado do Rio de Janeiro, usaram os seguintes materiais:

1ํ - Sensor Agulha: Consiste de uma agulha de aço inoxidável da Fenwall Electronics (K1137A), com um fio aquecedor e um sensor de termistor em seu interior. $\mathrm{O}$ diâmetro da agulha é de $1 \mathrm{~mm}$ e seu comprimento é de
$90 \mathrm{~mm}$. Do conector, saem as conexões da resistência de aquecimento à fonte de alimentação e do termistor ao multímetro. A resistência elétrica do fio aquecedor é $360 \Omega$ e a do termistor, à temperatura de $25^{\circ} \mathrm{C}$, é $930 \Omega$.

2ำ - Fonte de Corrente Constante: É uma fonte ajustável entre 1 a 20 VCC, por meio de um potenciômetro no painel frontal. Este módulo faz a conversão de voltagem/energia de 110 VCA para 20 VCC / $150 \mathrm{~mA}$. Os terminais do fio aquecedor são conectados à fonte de corrente contínua e os do termistor ao multímetro. No painel traseiro, encontra-se um conector BNC com saída de sinal de $5 \mathrm{~V} / 1 \mathrm{~Hz}$ com a finalidade de habilitar 0 multímetro para as leituras de resistência elétrica.

3ำ - Multímetro: Este instrumento é utilizado no sistema experimental para a leitura de resistência elétrica. Recebe o sinal para leituras, por meio do conector 'External Trigger', vindo da fonte de corrente constante e, depois, envia as leituras efetuadas ao computador por meio de um cabo serial RS-232.

4 - Computador: É utilizado para a aquisição automática de dados. Recebe as leituras do multímetro via cabo serial RS-232. A aquisição dos dados é facilitada com o uso de um programa em linguagem BASIC.

No caso de sedimentos a agulha é inserida num recipiente contendo a amostra. A geometria do ensaio é obviamente de meio infinito, já que o calor liberado na agulha flui em todas direções. No caso de amostras sólidas utiliza-se uma placa base de poliestireno expandido, que serve como isolante térmico, simulando desta forma 0 caso do meio semi-infinito para propagação de calor liberado na agulha. A amostra é colocada de forma a cobrir a parte central da agulha. Daí, ao acionar a fonte, inicia-se a liberação de calor no interior da agulha, o que induz na mesma, variações de temperatura. O aumento de temperatura da agulha depende em grande parte do fluxo de calor para a amostra, o que, por sua vez, é proporcional a sua condutividade térmica (Gomes e Hamza, 2003).

O diagrama esquemático deste arranjo experimental é ilustrado na Figura (2).

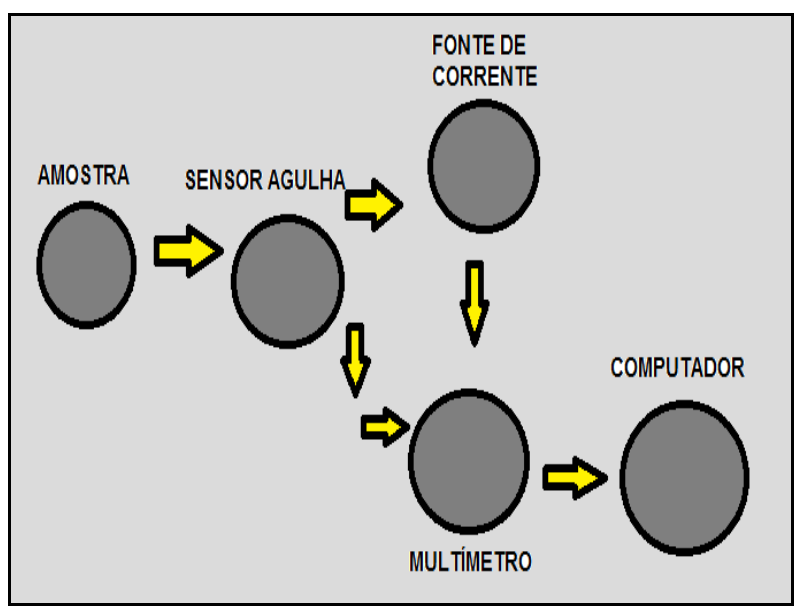


Figura 2 - Esquema experimental para medição de condutividade térmica pelo método da fonte linear de calor (Gomes e Hamza, 2003).

O sistema é calibrado através de um disco padrão, cuja condutividade térmica é conhecida.

b) Fonte Planar de Calor: O método de fonte planar de calor foi desenvolvido inicialmente por Mongelli (1968). O princípio deste método é baseado na solução da equação de transmissão de calor apropriada (Carslaw e Jaeger, 1959):

$$
T=Q\left(\frac{\operatorname{toc}}{\pi \lambda}\right)^{2} e^{\left(\frac{\left(x-x^{2}\right)^{2}}{4 k t}\right)}-\frac{Q\left|x-x^{2}\right|}{2 \kappa \rho c} \operatorname{erfc} \frac{|x-x|}{2 \sqrt{k t}}
$$

Onde:

Q é a taxa de produção de calor por unidade de tempo e área unitária;

$\lambda$ é a condutividade térmica;

t é o tempo após o início do ensaio;

T é a temperatura;

K é a difusividade térmica.

A relação entre a temperatura $(T)$ e o tempo (t) permite a determinação da condutividade térmica da amostra, desde que se conheça o valor efetivo de $(Q)$.

O dispositivo experimental para o método de Fonte planar de Calor utilizado no trabalho de Gomes e Hamza (2003) foi da marca Isomet, modelo 104 fabricada pela companhia 'AppliedPrecision', da República Slovákia. O desenho esquemático deste equipamento é ilustrado na Figura (3).

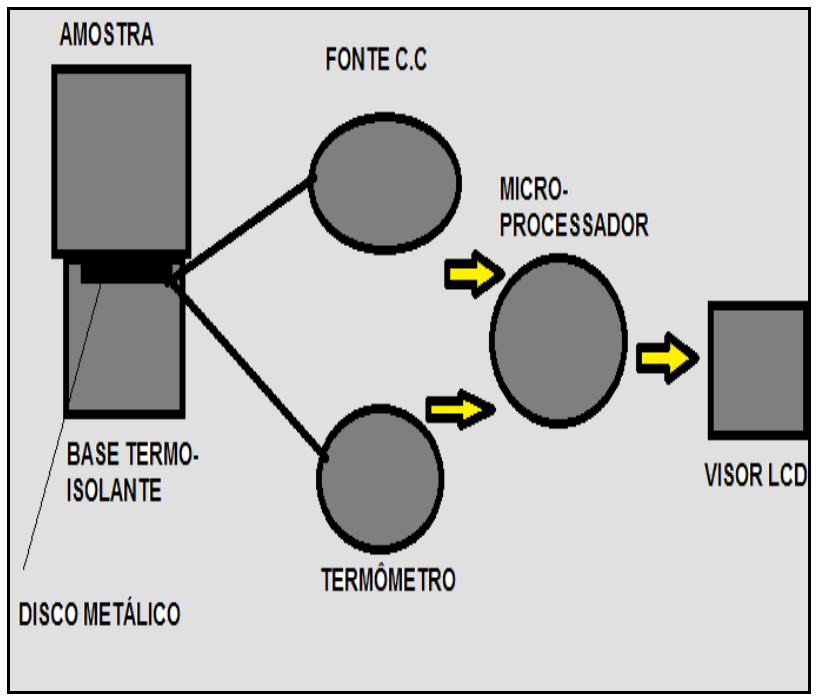

Figura 3 - Desenho esquemático do equipamento ISOMET para medição de condutividade térmica (Gomes e Hamza, 2003).
Entende-se que o núcleo da Terra é muito mais quente do que a superfície, e assim sendo, segundo as leis da termodinâmica, é tendente que haja um fluxo de calor no sentido centro-superfície em busca do equilíbrio térmico do sistema.

A energia que chega à superfície, é transportada mais significadamente por meio da condução de calor, pois de acordo Incropera \& Witt (1981) a transmissão de calor por condução é característica do transporte através dos sólidos. As entidades responsáveis por este transporte são os elétrons de condução e/ou as vibrações da rede cristalina. Nesse caso, esses sólidos citados são as rochas, e aí entra em cena a condutividade térmica.

A condutividade térmica é uma grandeza física fundamental nas mais variadas áreas científicas, podendo ser definida como a capacidade ou habilidade que um material possui de conduzir calor (energia em trânsito), sendo essa matematicamente quantificada, que dentre outras coisas, depende do tipo de rocha, dos minerais que a constituem (cada um desses terá sua própria condutividade térmica), da pressão e temperatura a qual está submetida e da estrutura ou forma do cristal. Por essa diversidade de dependências, avaliar a condutividade térmica das rochas é uma ação bem complexa, isso é confirmado por Figueiredo (2006) que afirma que ao se variar proporções entre os minerais ou a orientação dos cristais, mesmo que minimamente, a condutividade também sofrerá modificações.

Outro ponto a ser ressaltado é que as rochas não são isotrópicas e, portanto, deve-se considerar o efeito da anisotropia sobre elas. Seipold \& Huenges (1997) ratificam 0 efeito da anisotropia e afirmam que geralmente a condutividade térmica é baixa na direção perpendicular e mais alta na direção paralela ao plano de foliação. Estes autores afirmam ainda que este efeito pode sofrer variações importantes quando a lineação for bem marcada.

Sabendo que a Terra está em constante modificação, e por consequência suas rochas também, pode-se concluir que a condutividade térmica das regiões geológicas também está em processo de mudança no decorrer do tempo (geológico), esse raciocínio é mais uma evidência da complexidade de análise dessa grandeza física.

É importante destacar também, que quanto maior for à condutividade térmica de um determinado material, mais rápido este irá conduzir calor.

Portanto, no caso das rochas, quando se tem uma considerável constituição de quartzo (mineral bom condutor) numa rocha, a tendência é que o calor seja conduzido mais rapidamente nesta, comparando-se com rochas que possuem maior constituição de biotita, por exemplo, uma vez que a condutividade térmica do quartzo é muito maior do que a da biotita a nível mineralógico.

\section{Condutividade Térmica no Complexo Juiz de Fora}

Como parte de um programa de Energia Geotérmica dos Vales do Jequitinhonha e Mucuri iniciado em 2010, e também com o objetivo de se realizar uma avaliação de recursos geotermais da região, faz-se necessário conhecer as variações da condutividade térmica 
relacionadas com a geologia a nível regional. Em revisão bibliográfica, foram analisados os resultados de Gomes e Hamza (2003) e Gomes (2004) com a classificação por tipos litológicos que são apresentados na Tabela (1).

Tabela 1 - Condutividade térmica média dos principais tipos litológicos por Gomes e Hamza (2003) e Gomes (2004). O desvio padrão é representado por $\sigma$.

\begin{tabular}{|c|c|c|c|}
\hline \multirow[t]{2}{*}{ Grupo } & \multirow[t]{2}{*}{ Tipo Litológico } & \multicolumn{2}{|c|}{$\begin{array}{l}\text { Condut. } \\
\text { Térmica } \\
\text { (W/m.K) }\end{array}$} \\
\hline & & Média & $\sigma$ \\
\hline \multirow{6}{*}{$\begin{array}{c}\text { Rochas } \\
\text { Sedimentares }\end{array}$} & $\begin{array}{c}\text { Areia Média } \\
\text { Grossa }\end{array}$ & 2,8 & 0,8 \\
\hline & $\begin{array}{l}\text { Areia Média } \\
\text { Angilosa }\end{array}$ & 2,2 & 0,8 \\
\hline & Arenito Médio & 2,7 & 0,8 \\
\hline & $\begin{array}{c}\text { Não } \\
\text { Classificados }\end{array}$ & 2,7 & 0,8 \\
\hline & $\begin{array}{l}\text { Sedimentos } \\
\text { Fluviais }\end{array}$ & 2,7 & 0,8 \\
\hline & Siltito & 2,7 & 1,3 \\
\hline \multirow{3}{*}{$\begin{array}{l}\text { Metamórfica de } \\
\text { Baixo Grau }\end{array}$} & Anfibolito & 3,3 & 1,6 \\
\hline & Calcissilicática & 2,4 & 1 \\
\hline & Quartzito & 3,1 & 1 \\
\hline \multirow{8}{*}{$\begin{array}{c}\text { Metamórfica de Alto } \\
\text { Grau }\end{array}$} & Biotita Gnaisse & 3,5 & 2 \\
\hline & $\begin{array}{l}\text { Gnaisse } \\
\text { Bandado }\end{array}$ & 3 & 2 \\
\hline & Gnaisse Facoidal & 4,3 & 2,4 \\
\hline & $\begin{array}{l}\text { Gnaisse } \\
\text { Granítico }\end{array}$ & 3,1 & 2,1 \\
\hline & $\begin{array}{c}\text { Gnaisse } \\
\text { Leucocrático }\end{array}$ & 2,8 & 1,2 \\
\hline & $\begin{array}{c}\text { Gnaisse } \\
\text { Mesocrático }\end{array}$ & 3,9 & 1 \\
\hline & $\begin{array}{l}\text { Granada- } \\
\text { Gnaisse }\end{array}$ & 4,4 & 3 \\
\hline & Granulito & 3,3 & 1,7 \\
\hline \multirow{5}{*}{$\begin{array}{c}\text { Rochas Ígneas } \\
\text { Ácidas }\end{array}$} & Granito & 3,1 & 1,3 \\
\hline & $\begin{array}{c}\text { Granito } \\
\text { Diferenciado }\end{array}$ & 2,7 & 1,5 \\
\hline & Granito Porfirítico & 2,6 & 0,7 \\
\hline & Granitóide & 3 & 1,7 \\
\hline & $\begin{array}{l}\text { Granitóide } \\
\text { Tonalítico } \\
\end{array}$ & 3,1 & 1,3 \\
\hline $\begin{array}{c}\text { Rochas Ígneas } \\
\text { Básicas }\end{array}$ & Diabásio & 2,6 & 0,7 \\
\hline
\end{tabular}

Com relação aos resultados de Condutividade Térmica obtidos nesta compilação e predominantemente sobre 0 complexo de Juiz de Fora (Gomes e Hamza, 2003, Gomes, 2004, Hamza et al, 2005, e Gomes e Alexandrino, 2011) constata-se que os principais valores conhecidos experimentalmente, são apresentados a seguir na Tabela (2), onde o valor do desvio padrão é representado por $\sigma$.

Tabela 2 - Valores da condutividade térmica na formação geológica do Complexo Juiz de Fora (Gomes e Hamza, (2003), Gomes (2004) e Gomes et al (2011).

\begin{tabular}{|c|c|c|c|}
\hline Formação & Tipo Litológico & \multicolumn{2}{|c|}{$\begin{array}{c}\text { Condutividade } \\
\text { (W/(m.K) }\end{array}$} \\
\cline { 2 - 4 } & & Média & $\Sigma$ \\
\hline \multirow{4}{*}{$\begin{array}{c}\text { Complexo } \\
\text { Juiz de } \\
\text { Fora }\end{array}$} & Granitóide & 3,0 & 1,7 \\
\cline { 2 - 4 } & Gnaisse & 3,0 & 1,2 \\
\cline { 2 - 4 } & Gnaisse Migmatito & 3,0 & 1,2 \\
\cline { 2 - 4 } & Granito & 3,1 & 2,1 \\
\cline { 2 - 4 } & Quartzito & 3,1 & 1,3 \\
\cline { 2 - 4 } & Anfibolito & 3,3 & 1,6 \\
\cline { 2 - 4 } & Biotita Gnaisse & 3,5 & 2,0 \\
\hline \multirow{4}{*}{$\begin{array}{c}\text { Paraíba } \\
\text { do Sul }\end{array}$} & Granulito & 3,3 & 1,7 \\
\cline { 2 - 4 } & Biotita Gnaisse & 3,1 & 1,3 \\
\cline { 2 - 4 } & Gnaisse & 3,5 & 2,0 \\
\hline \multicolumn{2}{|c|}{ Média Geral } & $\mathbf{3 , 2}$ & $\mathbf{1 , 6}$ \\
\hline
\end{tabular}

Levando em consideração apenas a análise litológica dos valores da Tabela (2) determinou-se que a média da condutividade térmica é $3,2 \mathrm{~W} / \mathrm{m}$.K e desvio padrão de $1,6 \mathrm{~W} / \mathrm{m} . \mathrm{K}$ para o Complexo Juiz de Fora.

\section{Resultados e Discussões}

Os resultados obtidos através da utilização dos dois métodos já descritos e revisões bibliográficas são exibidos no gráfico apresentado no final deste trabalho com os tipos litológicos do Complexo Juiz de Fora, contendo os valores de condutividade térmica e seus respectivos desvios feitos em literatura relevante de pesquisas realizadas. "A vantagem principal deste instrumento é a presença do módulo interno do microprocessador que automatiza a coleta de dados sobre a variação de temperatura do disco metálico durante o ensaio e integração de curva de tempo temperatura. O visor LCD ('Liquid Crystal Display') apresenta valor de condutividade térmica como resultado final desta aquisição e do processamento. A outra vantagem deste instrumento é a capacidade do seu microprocessador para implementar algoritmos do procedimento complementar sugerido inicialmente por Jaeger (1959), pelo qual é possível determinar a difusividade térmica da amostra. A disponibilidade de valores de condutividade e a difusividade permitem ainda o cálculo de calor específico." (Gomes e Hamza, 2003). 
Os resultados obtidos através da utilização dos dois métodos já descritos e revisões bibliográficas serão exibidos também com a utilização de gráficos de condutividade dos tipos de rochas que constituem 0 Complexo Juiz de Fora, conforme figura (4) abaixo.

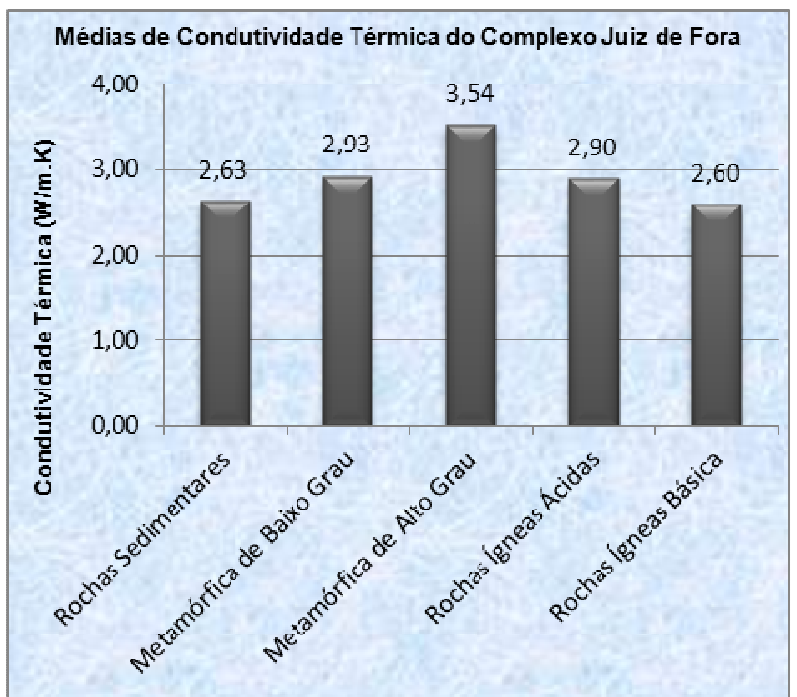

Figura 4 - Média dos valores de condutividade térmica das principais rochas do Complexo Juiz de Fora (Gomes e Hamza, 2003; Gomes, 2004, Hamza et al, 2005, e Gomes e Alexandrino, 2011).

Analise por estado realizadas com base em trabalhos de Gomes e Hamza (2003); Gomes (2004), Hamza et al (2005) e Gomes e Alexandrino (2011), fornecem uma variação da condutividade térmica do Complexo Juiz de Fora no estado do Rio de Janeiro entre 2,2 - 4,0 W/m.k, e em Minas Gerais 2,5-4,0 W/m.k.

Com base nos dados e fazendo uma média geral, apresentado abaixo na tabela (1) valores médios de condutividade térmica dos Estados do Rio de Janeiro e de Minas Gerais.

Tabela 1 - Valores de Condutividade Térmica do Complexo Juiz de Fora nos estados do Rio de Janeiro e Minas Gerais (Adaptado Gomes e Hamza, 2003, Gomes, 2004, Hamza et al, 2005, Gomes e Alexandrino, 2011).

\begin{tabular}{|c|l|c|}
\hline \multicolumn{3}{|c|}{ Valores de Condutividade Térmica por Estado } \\
(W/m.K)
\end{tabular}

O resultado observado nos valores de Condutividade Térmica, entre as rochas situadas no Estado do Rio de Janeiro e as do Estado de Minas Gerais, mostram ser mais condutivas as do Complexo em Minas Gerais.

\section{Conclusões}

Os dados analisados apontam que os valores obtidos para o Complexo Juiz de Fora, tanto com o método da
Fonte Linear, quanto o da Fonte Planar, resultaram num valor médio da condutividade térmica de $3,2(\mathrm{~W} / \mathrm{m} . \mathrm{K})$ e o desvio padrão de $\pm 1,6$ (W/m.K).

As rochas de alto Grau Metamórfico tendem a ser mais condutivas termicamente no Estado de Minas Gerais do que as demais no Rio de Janeiro.

As rochas básicas do complexo apresentam valores mais baixos que as ácidas, respectivamente 2,60 e 3,54 (W/m.K).

O valor médio apresentado poderá ser utilizado em estudos referentes a avaliações geotérmicas em locais que estão sob o Complexo Juiz de Fora sobretudo em avaliações de recursos geotermais.

\section{Referências}

GOMES, A. J. L. ; HAMZA, V.M., 2003. Avaliação de Recursos Geotermais do Estado do Rio de Janeiro. In: $7^{\circ}$ International Congress of the Brazilian Geophysical Society, Rio de Janeiro.

Gomes, A.J.L. 2004. Avaliação de Recursos Geotermais do Estado do Rio de Janeiro. Dissertação de Mestrado, Observatório Nacional, Rio de Janeiro.

Gomes, A.J.L. e Alexandrino, C.H. 2011. Mapeamento de Gradiente Geotérmico do Município De Teófilo Otoni no Estado De Minas Gerais. In: 12th International Congress of The Brazilian Geophysical Society.

Gomes, A. J. L.; Ramalho, A.M. ; Petzold, A.S. ; Santos, G.M.; Silva, J.M.P.; Campos, P.C.O. 2011. Gradiente Geotérmico do Município de Teófilo Otoni no Estado de Minas Gerais. In: 12th International Congress Of The Brazilian Geophysical Society, Rio de Janeiro Brasil.

Hamza, V.M., Silva Dias, F.J.S., Gomes, A.J.L. and Terceros, Z.G.D., 2005. Numerical and Functional Representations of Regional Heat Flow in South America, Physics of the Earth and Planetary Interiors, Volume 152, 4, p.223-256.

Noce, C. M.; Soares, A. C. P.; SILVA, L. C.; ALKMIM, F. F., 2007. O Embasamento Arqueano e Paleoproterozóico do Orógeno Araçuaí. GEONOMOS 15(1): 17 - 23.

Heilbron M. 1993. "Evolução tectono-metamórfica da Seção Bom Jardim de Minas (MG) - Barra do Piraí (RJ)". Setor Central da Faixa Ribeira. Tese de Doutoramento, Instituto de Geociências, Univ. de São Paulo, 268 p.

Heilbron M. 1995. O Segmento Central da Faixa Ribeira: Compartimentação Tectônica e Ensaio Evolutivo. Tese de Livre Docência, Universidade Estadual do Rio de Janeiro, $115 p$.

Silva, C. M. T.; Alkmim, F. F.; Soares, A. C. P. 2009. "Geometria e evolução do feixe de zonas de cisalhamento Manhuaçu - Santa Margarida, Orógeno Araçuaí, MG". : R. Esc. Minas, Ouro Preto, 62(1): 23-34p; 


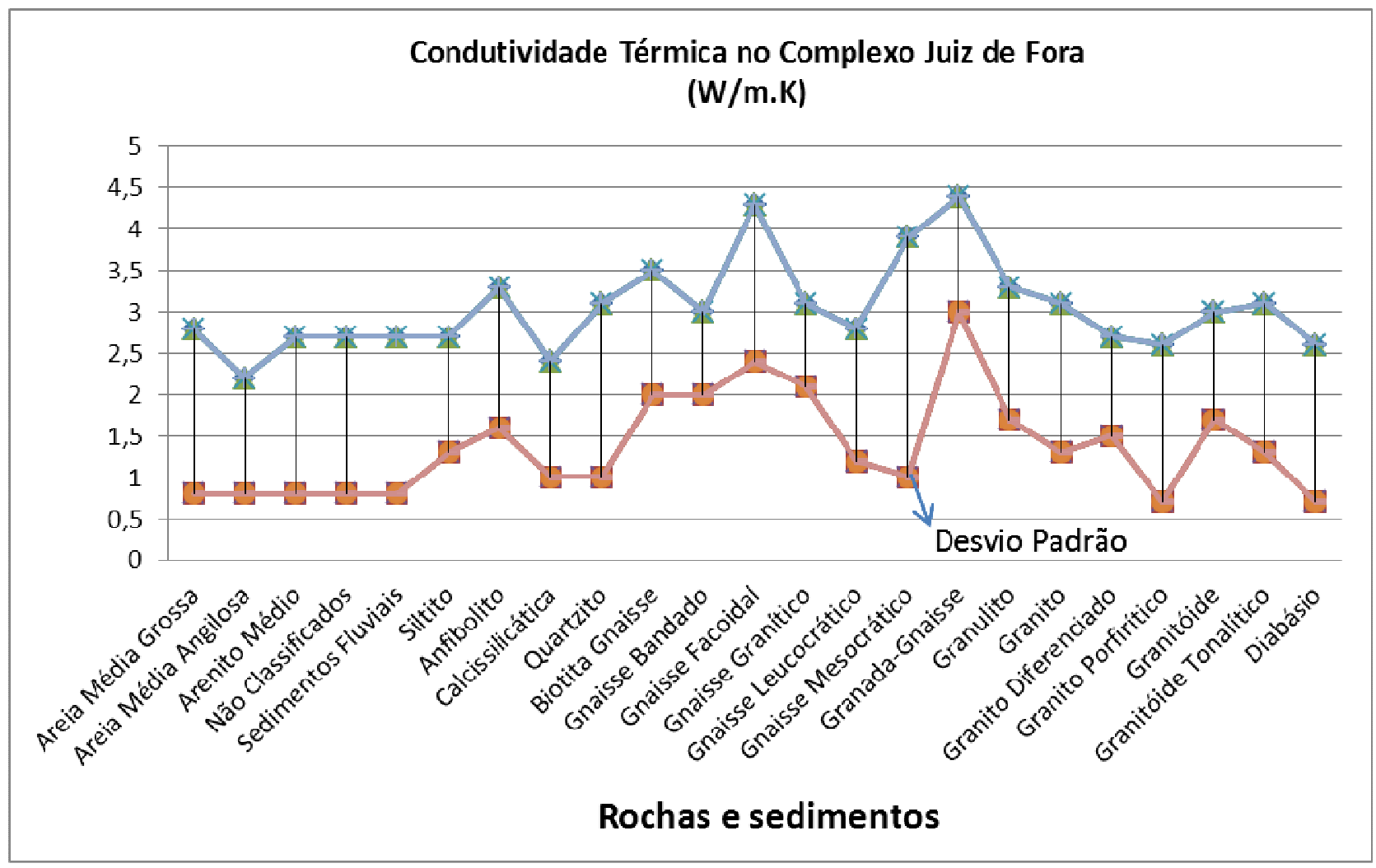

Figura 5 - Média dos valores de condutividade térmica das rochas e sedimentos do Complexo Juiz de Fora.

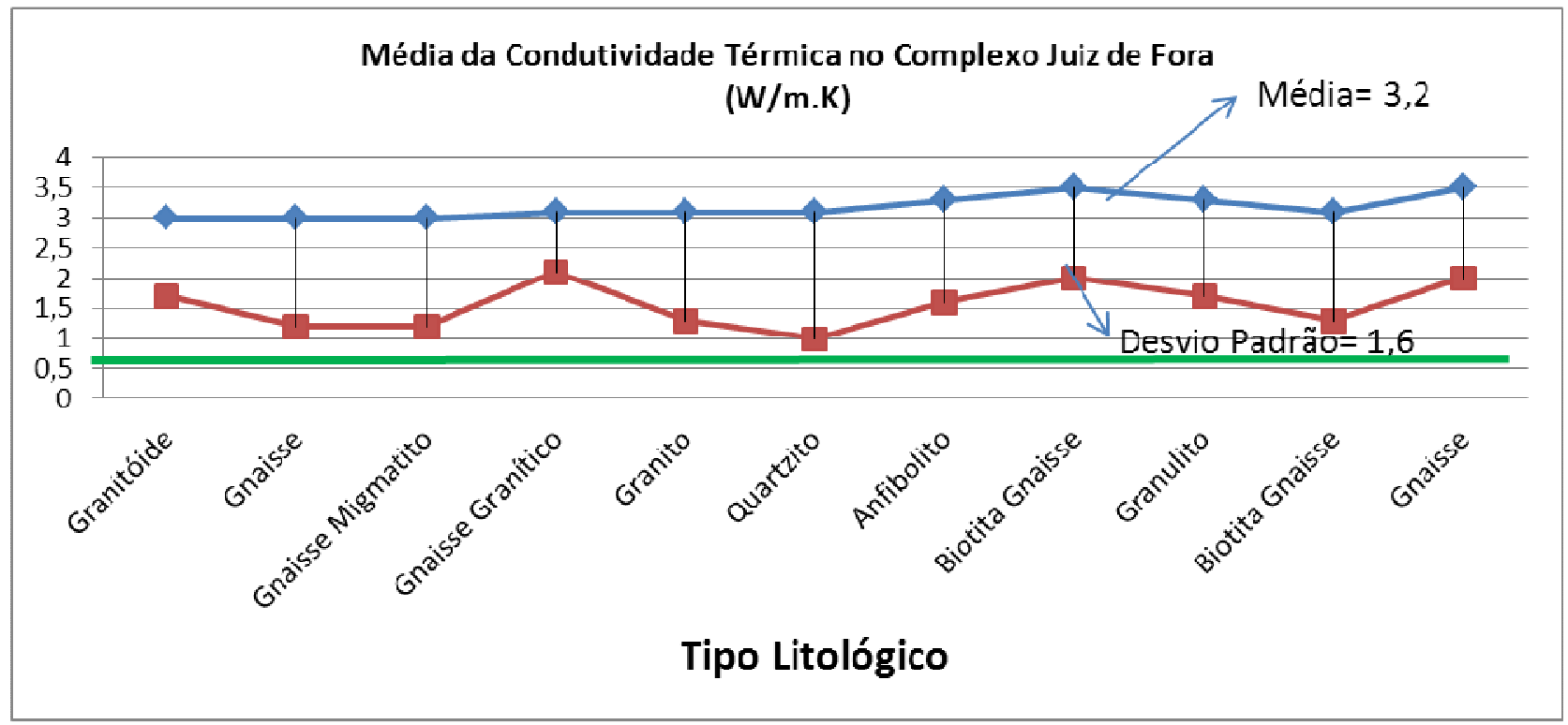

Figura 6 - Média de condutividade térmica dos valores dos tipos litológicos do Complexo Juiz de Fora. 